\title{
Air Stable, High Efficiency, PtBased Halide Perovskite Solar Cells with Long Carrier Lifetimes
}

Schwartz, Dakota; Murshed, Rubaiya; Larson, Harry; Usprung, Benedikt; Soltanmohamad, Sina; Pandey, Ramesh; Barnard, Edward S.; Rockett, Angus; Hartmann, Thomas; Castelli, Ivano Eligio

Total number of authors:

11

Published in:

Physica Status Solidi. Rapid Research Letters

Link to article, DOI:

10.1002/pssr.202000182

Publication date:

2020

Document Version

Peer reviewed version

Link back to DTU Orbit

Citation (APA):

Schwartz, D., Murshed, R., Larson, H., Usprung, B., Soltanmohamad, S., Pandey, R., Barnard, E. S., Rockett, A., Hartmann, T., Castelli, I. E., \& Bansal, S. (2020). Air Stable, High Efficiency, PtBased Halide Perovskite Solar Cells with Long Carrier Lifetimes. Physica Status Solidi. Rapid Research Letters, 14(8), [2000182].

https://doi.org/10.1002/pssr.202000182

\section{General rights}

Copyright and moral rights for the publications made accessible in the public portal are retained by the authors and/or other copyright owners and it is a condition of accessing publications that users recognise and abide by the legal requirements associated with these rights.

- Users may download and print one copy of any publication from the public portal for the purpose of private study or research.

- You may not further distribute the material or use it for any profit-making activity or commercial gain

- You may freely distribute the URL identifying the publication in the public portal 


\section{Air Stable, High Efficiency, Pt-Based Halide}

\section{Perovskite Solar Cells with Long Carrier Lifetimes}

Dakota Schwartz ${ }^{a}$, Rubaiya Murshed ${ }^{a}$, Harry Larson $^{a}$, Benedikt Usprung $^{b, c}$, Sina Soltanmohamad ${ }^{d}$ Ramesh Pandey ${ }^{e}$, Edward S. Barnard ${ }^{c}$, Angus Rockett ${ }^{d}$, Thomas Hartmann ${ }^{a}$, Ivano E. Castelli ${ }^{\dagger f}$, Shubhra Bansal ${ }^{* a}$

${ }^{a}$ Department of Mechanical Engineering, University of Nevada Las Vegas, Las Vegas NV, USA.

*Email: Shubhra.bansal@unlv.edu

${ }^{b}$ Department Of Mechanical Engineering, Columbia University, New York, New York, USA.

${ }^{c}$ Molecular Foundry, Lawrence Berkeley National Laboratory, Berkeley CA, USA.

${ }^{d}$ Department of Materials Science and Engineering, Colorado School of Mines, Golden CO, USA.

${ }^{e}$ Department of Physics, Colorado State University, Fort Collins, CO, USA.

${ }^{f}$ Department of Energy Conversion and Storage, Technical University of Denmark, Lyngby, Denmark.

Corresponding Author: Email: Shubhra.bansal@unlv.edu

† For DFT calculations contact Ivano Castelli. Email: ivca@dtu.dk

This article has been accepted for publication and undergone full peer review but has not been through the copyediting, typesetting, pagination and proofreading process, which may lead to differences between this version and the Version of Record. Please cite this article as doi: $10.1002 /$ pssr.202000182. 


\section{ABSTRACT}

The search for $\mathrm{Pb}$-free perovskite materials continues with limited success to find a suitable replacement for $\mathrm{Pb}$ with outstanding optoelectronic properties. Here we report $\mathrm{Pb}$-free inorganic halide perovskite $\mathrm{Cs}_{2} \mathrm{PtI}_{6}$ with excellent absorption coefficient, long minority carrier lifetime and optical bandgap of $1.4 \mathrm{eV}$. Atmospheric precursor based solution processing results in high quality $\mathrm{Cs}_{2} \mathrm{PtI}_{6}$ with absorption coefficient of $4 \times 10^{5} \mathrm{~cm}^{-1}$ for photon energies $>1.5 \mathrm{eV}$ and high minority carrier lifetimes of $>2 \mu$ s indicating low defect density in the material. Superstrate $n-i-p$ solar cells processed with the structure $\mathrm{F}: \mathrm{SnO}_{2} / \mathrm{CdS} / \mathrm{Cs}_{2} \mathrm{PtI}_{6} /$ carbon/Cu show promising device efficiency of 13.88\%. These planar devices processed under atmospheric conditions show low $\mathrm{V}_{\mathrm{oc}}$ deficit $(<0.3$ V) without any hysteresis in forward and reverse scans indicating low trap densities. Pt offers an excellent model system for replacement of $\mathrm{Pb}$ due to high atomic number, oxidation resistance and stability. $\mathrm{Cs}_{2} \mathrm{PtI}_{6}$ is an atmospherically stable phase under $\mathrm{AM} 1.5 \mathrm{G}$ and $65^{\circ} \mathrm{C}$ upto 1000 hours.

Organic-inorganic hybrid halide perovskite solar cells (HPSCs) have attracted immense attention because of excellent optoelectronic properties and record power conversion efficiency (PCE) has reached $25.2 \%$ from $3.8 \%$ within a few years. ${ }^{[1-6]}$ Despite the very high efficiency already attained by HPSCs $\left(\mathrm{ABX}_{3} ; \mathrm{A}=\mathrm{MA}, \mathrm{FA}, \mathrm{Cs} ; \mathrm{B}=\mathrm{Pb}, \mathrm{Sn} ; \mathrm{X}=\mathrm{I}, \mathrm{Br}, \mathrm{Cl}\right)$ resulting from high absorption coefficient and electron-hole diffusion lengths; toxicity of $\mathrm{Pb}$ and stability of these materials are veritable issues. Replacing $\mathrm{MA}^{+}$and $\mathrm{FA}^{+}$with $\mathrm{PEA}^{+}, \mathrm{BA}^{+}, \mathrm{Cs}^{+}$has shown to enhance the stability of hybrid perovskite solar cells against thermal and moisture related degradation. ${ }^{[7-11]}$ The superior optoelectronic properties of $\mathrm{Pb}$-based halide perovskites are attributed to the inactive $\mathrm{Pb} 6 \mathrm{~s}$ orbitals, and can be replaced by $\mathrm{Ge}^{2+}, \mathrm{Sn}^{2+}, \mathrm{Sb}^{3+}, \mathrm{Bi}^{3+}, \mathrm{Cu}^{2+}$ with inactive s orbitals. Replacement of $\mathrm{Pb}^{2+}$ with $\mathrm{Sn}^{2+}$ and $\mathrm{Ge}^{2+}$ seems to be a logical solution for addressing the toxicity issues and results in excellent optoelectronic properties such as high absorption coefficient, high hole mobility resulting This article is protected by copyright. All rights reserved 
in PCE of $9.6 \%$ for $(\mathrm{GA}, \mathrm{FA}) \mathrm{SnI}_{3}{ }^{[12]}$ and $7.9 \%$ for mixed (FA,MA) $\mathrm{GeSnI}_{3}{ }^{[13]}$ and $7.11 \%$ for $\mathrm{CsSn}_{0.5} \mathrm{Ge}_{0.5} \mathrm{I}_{3} \cdot{ }^{[14]}$ However, a major challenge for $\mathrm{Sn}$ and $\mathrm{Ge}$ based $\mathrm{Pb}$-free perovskites is poor power conversion efficiencies as divalent $\mathrm{Sn}^{2+}$ and $\mathrm{Ge}^{2+}$ tend to oxidize into 4+ oxidation state, generating excessive defects ( $\mathrm{Sn}$ and Ge vacancies), and resultant short carrier diffusion lengths. The $2 \mathrm{D}$ structure $\mathrm{Cs}_{2} \mathrm{SnI}_{6}$ has received attention as a more stable alternative to $\mathrm{CsSnI}_{3}$ based halideperovskites for photovoltaic applications due to stable $\mathrm{Sn}^{4+}$ oxidation state and the strong covalency of Sn-I bonds in the $\left[\mathrm{SnI}_{6}\right]^{2-}$ octahedral. ${ }^{[15-25]} \mathrm{Cs}_{2} \mathrm{PdBr}_{6}, \mathrm{Cs}_{2} \mathrm{TiBr}_{6}, \mathrm{Cs}_{2} \mathrm{AgBiX}_{6}, \mathrm{CsGe}_{0.5} \mathrm{Sn}_{0.5} \mathrm{I}_{3}$, $\mathrm{AgBiI}_{4},(\mathrm{MA}, \mathrm{Cs}, \mathrm{Rb})_{3} \mathrm{Sb}_{2} \mathrm{I}_{9}$ have been shown to be unsuitable for PV applications due to many reasons such as bandgap $>2 \mathrm{eV}$, low minority carrier diffusion lengths, deep level defects, resulting in high $\mathrm{V}_{\mathrm{oc}}$ deficit and poor PCEs. ${ }^{[26-34]}$

In this work, we report for the first time Pt-based photoabsorber, $\mathrm{Cs}_{2} \mathrm{PtI}_{6}$ which has been synthesized by atmospheric solution processing from CsI and $\mathrm{PtI}_{4}$ precursors in a solvent mixture of dimethylformamide (DMF), dimethyl sulfoxide (DMSO) and $\gamma$-butyrolactone (GBL). $\mathrm{Cs}_{2} \mathrm{PtI}_{6}$ crystallizes with sharp Bragg peaks corresponding to $F m \overline{3} m$ spacegroup with bandgap of $1.4 \mathrm{eV}$, hole mobility of $\sim 62.6 \mathrm{~cm}^{2} /$ V.s and minority carrier lifetime of $>2 \mu$. Preliminary superstrate $n-i-p$ devices fabricated using CdS electron transport layer (ETL) show best PCE of $13.88 \%$ with use of ethylene diamine (EDA) treatment for $\mathrm{Cs}_{2} \mathrm{PtI}_{6}$ based devices, one of the best efficiency and opencircuit voltages for $\mathrm{Pb}$-free perovskites. The cost of $\mathrm{Pt}$ can be considered prohibitive for photovoltaic applications, however, Pt provides an excellent model system for replacement of $\mathrm{Pb}$.

Figure 1 illustrates schematically the precursor based solution process used for deposition of $\mathrm{Cs}_{2} \mathrm{PtI}_{6}$ perovskite thin-films. The vacancy ordered perovskite $\mathrm{Cs}_{2} \mathrm{PtI}_{6}$ is synthesized using doctor blade process in atmospheric conditions resulting in cubic crystals of the $F m \overline{3} m$ space group. Figure 2a shows X-ray diffraction (XRD) pattern for thin-films prepared on glass with $\mathrm{PtI}_{4}$ based precursors in a solvent combination of DMF:DMSO with and without EDA. $\mathrm{Cs}_{2} \mathrm{PtI}_{6}$ phase can also be processed $\mathrm{PtI}_{2}$ precursor in a solvent combination of DMF:GBL, however, the best quality films 
result from $\mathrm{CsI}+\mathrm{PtI}_{4}$ precursors in DMF:DMSO. Films deposited using $\mathrm{CsI}+\mathrm{PtI}_{2}$ precursor in DMF:GBL results in ordered tetragonal and cubic $\mathrm{Cs}_{2} \mathrm{PtI}_{6}$ phase (ICDD 04-011-1068) as determined by splitting of (222), (400), (440), (622) peaks. The unit cell parameter is estimated as $8.3 \dot{A}$ in the $F m \overline{3} m$ space group in good agreement with the structural data and the films exhibit a preferred orientation with enhanced $\{111\}$ peak intensities. Due to the solutes used, it is expected that the DMF:GBL sample with $\mathrm{PtI}_{2}$ based precursor has excess platinum in addition to $\mathrm{Cs}_{2} \mathrm{PtI}_{6}$ phase, which is confirmed by the high-intensity 39.7 degrees peak indicating preferred orientation along (511) for $\mathrm{Cs}_{2} \mathrm{PtI}_{6}$ or (111) Pt peaks. Pt can be expected as precipitates or interstitials, which may explain the lattice strain resulting in peak splitting. No preferred orientation is observed for $\mathrm{PtI}_{4}$ based precursors in DMF:GBL, but these films showed poor adhesion and could not be used for characterization or device fabrication. With the use of DMF:DMSO solvent mixture with $\mathrm{PtI}_{4}$ results in well-crystallized $\mathrm{Cs}_{2} \mathrm{PtI}_{6}$ structure as determined by the (111), (200), (220), (222), (400), (440), (622) peaks. No residual CsI or $\mathrm{PtI}_{4}$ peaks are observed in XRD for $\mathrm{Cs}_{2} \mathrm{PtI}_{6}$, however, the peak doublets indicate lattice strain and can be fitted to the tetragonal and cubic standard patterns for $\mathrm{Cs}_{2} \mathrm{PtI}_{6}$. Composition of the thin-films determined by electron dispersive spectroscopy (EDS) and X-ray phototelectron spectroscopy (XPS) are in agreement with 15-19 at.\% Cs, 9 at.\% Pt, 45-58 at.\% I, $~ 5$ at.\% $\mathrm{Cl}$, and residual 25 at.\% of $\mathrm{O}, \mathrm{C}, \mathrm{K}$. ToF-SIMS data also confirms presence of $\mathrm{Cl}$ well intermixed with I as shown in inset of Figure 2b. EDS, XPS and ToF-SIMS data indicate presence of chlorine in films prepared with $\mathrm{PtI}_{4}$ based precursors which is an impurity in $\mathrm{PtI}_{4}$ solutes (99.95\% metal basis). Figures 2c-e show top-down and cross-sectional scanning electron microscopy (SEM) micrographs for $\mathrm{Cs}_{2} \mathrm{PtI}_{6}$ films. For films deposited without EDA post-treatment a large density of pinholes is observed, but the use of EDA results in surface recrystallization. Further improvement in morphology and reduction of pinhole density will be needed to develop high quality polycrystalline films. Iodides of PPA (3-phenyl-2-propen-1-amine) additives have shown to assist the growth of uniform grains and passivation of grain boundaries. ${ }^{[35,36]}$ 
Figure $3 \mathrm{a}$ shows the absorption coefficient vs. wavelength plots and steady-state photoluminescence (PL) emission spectrum for films prepared using $\mathrm{PtI}_{4}$ based precursors in DMF:DMSO solvent mixtures with and without EDA. UV-Vis-NIR spectroscopy and Tauc plot analysis shows direct bandgap of 1.36-1.4 eV and possible indirect optical bandgap of $1.3 \mathrm{eV}$. The films also show high absorption coefficient at bandedge and high minority carrier lifetime as measured by TRPL. Bandgap of these films was also confirmed by photoluminescence measurements which show emission peak at $878 \mathrm{~nm}$ for $\mathrm{Cs}_{2} \mathrm{PtI}_{6}$ films which slightly smaller than predicted with density functional theory (DFT) results for $\mathrm{Cs}_{2} \mathrm{PtI}_{6}$ reported by Cai et al. ${ }^{[37]}$ of 1.463 $\mathrm{eV}$ and $1.472 \mathrm{eV}$ for cubic and tetragonal phases calculated using hybrid HSE06 functionals. The intensity of the PL peak for $\mathrm{Cs}_{2} \mathrm{PtI}_{6}$ suggests direct nature of the bandgap as also predicted by DFT calculations. Figure $3 \mathrm{~b}$ shows the minority carrier diffusion lifetime as determined by TRPL of $2.832 \mu \mathrm{s}$ and $2.693 \mu \mathrm{s}$ for $\mathrm{Cs}_{2} \mathrm{PtI}_{6}$ films with and without EDA. The improvement in the carrier lifetime resulted in devices with improved fill-factor (FF), also evident by high carrier collection in quantum efficiency curves. The absorption coefficient of $\mathrm{Cs}_{2} \mathrm{PtI}_{6}$ is repeatably measured as $4 \times 10^{5} \mathrm{~cm}^{-1}$ at photon energy $>1.5 \mathrm{eV}$ which is higher compared to $\mathrm{MAPbI}_{3}$ films. ${ }^{[5]} \mathrm{UV}-\mathrm{Vis}-\mathrm{NIR}$ spectroscopy measurements conducted on liquid precursors indicates $\mathrm{PtI}_{4}$ based precursors in DMF:DMSO shows adduct formation with Lewis base DMSO but upon annealing $\mathrm{Pt}^{4+}$ results in formation of $\mathrm{Cs}_{2} \mathrm{PtI}_{6}$. In order to further confirm the structure of $\mathrm{Cs}_{2} \mathrm{PtI}_{6}$, Raman spectroscopy measurements were conducted using $532 \mathrm{~nm}$ laser on $\mathrm{Cs}_{2} \mathrm{PtI}_{6}$ films deposited on glass. We observe sharp Raman peaks at $154 \mathrm{~cm}^{-1}, 175 \mathrm{~cm}^{-1}, 313 \mathrm{~cm}^{-1}, 343 \mathrm{~cm}^{-1}$, and $474 \mathrm{~cm}^{-1}$ as shown in Figure $3 \mathrm{c}$. ${ }^{\text {[38-41] }}$ The highest frequency longitudinal optical (LO) phonon mode expected for these $\mathrm{ABX}_{3}$ and $\mathrm{A}_{2} \mathrm{BX}_{6}$ perovskite structures is at $375 \mathrm{~cm}^{-1}$, and peaks below this can be assigned to symmetric and asymmetric bending and stretching of Pt-I bond and $474 \mathrm{~cm}^{-1}$ translational optical (TO) mode associated with vibrations in $\mathrm{PtI}_{6}$ octahedra. ${ }^{[41]}$ The high minority carrier lifetime and high absorption coefficient for $\mathrm{Cs}_{2} \mathrm{PtI}_{6}$ are very encouraging and present a potentially stable $\mathrm{Pb}$-free perovskite material with tunable bandgap for photovoltaic and other optoelectronic applications.

This article is protected by copyright. All rights reserved 
The calculated band structure of $\mathrm{Cs}_{2} \mathrm{PtI}_{6}$ shows that the material can exhibit both indirect and direct bandgaps with valence band derived primarily from I $p$ states, and conduction bands derived from hybridized Pt $d$ and I $p$ states. These calculations suggest that the conduction band minimum $(\mathrm{CBM})$ is slightly shifted in k-space with respect to valence band maximum (VBM), making the fundamental bandgap indirect. However, the experimentally observed high absorption coefficient indicates $\mathrm{Cs}_{2} \mathrm{PtI}_{6}$ behaves as a direct-bandgap semiconductor, where absorption and emission of photons occur via allowed transitions, but at the same time recombination rate is much slower, similar to $\mathrm{MAPbI}_{3}$ solar cells. In $\mathrm{MAPbI}_{3}$, this behavior has been attributed to the dipole moment of the organic cations in tetragonal and cubic crystal phases or due to spin-orbit-coupling (SOC) effects in $\mathrm{Pb}$. With the absence of organic cation in $\mathrm{Cs}_{2} \mathrm{PtI}_{6}$, SOC in Pt is a likely cause of indirect bandgap, although there is no clear evidence of split of conduction band due to Rashba splitting from our preliminary DFT calculations. Further experiments with temperature dependent TRPL and a rigorous analysis of absorption spectra may be needed to determine if the photo-excited carriers undergo a phonon-assisted recombination pathway.

To get more insight into the high absorption coefficient of $\mathrm{Cs}_{2} \mathrm{PtI}_{6}$ compared to $\mathrm{MAPbI}_{3}$, atomistic calculations were conducted using the ASE and GPAW codes and using the GLLBSC exchange correlation functional that has demonstrated very good results, comparable to many body and hybrid functionals methods, for the calculations of the electronic properties. Figure $4 \mathrm{~b}$ shows the band structure and projected density of states for $\mathrm{Cs}_{2} \mathrm{PtI}_{6}$, calculated by means of Density Functional Theory (DFT). It has a direct band gap of $0.85 \mathrm{eV}$ calculated for the structure at the experimental lattice parameters. This value underestimates the experimental band gap and the values reported by Cai et al. ${ }^{[37]}$ that were calculated with the hybrid functional HSE06, although, for structures with slightly overestimated lattice parameters. The Projected Density of States (PDOS) shows that the valence band is mainly composed of I- $p$ states, and the conduction band of Pt- $d$ states hybridized with I- $p$ orbitals. Comparing PDOS of $\mathrm{Cs}_{2} \mathrm{PtI}_{6}$ and $\mathrm{MAPbI}_{3}$ (Figure 4a), we 
note that the former is mostly formed by Pt- $d$ and I- $p$ states at the band gap edges, while the latter $\mathrm{Pb}-p$ and I- $p$ states. The strength of the $d-p$ transition of $\mathrm{Cs}_{2} \mathrm{PtI}_{6}$ compared with the $p-p$ transition of $\mathrm{MAPbI}_{3}$ might be the reason why the absorption coefficients of the former is higher than the ones of the latter. The calculated absorption spectra for these materials confirm these findings, although it starts later, the absorption of for $\mathrm{Cs}_{2} \mathrm{PtI}_{6}$ is steeper, as shown in Figure 4c.

To assess the photovoltaic properties of $\mathrm{Cs}_{2} \mathrm{PtI}_{6}$, we fabricated planar superstrate $n-i-p$ devices with the structure glass $/ \mathrm{F}: \mathrm{SnO}_{2} / \mathrm{CdS} / \mathrm{Cs}_{2} \mathrm{PtI}_{6} /$ carbon $/ \mathrm{Cu}$. As XPS analysis showed some surface oxides, an EDA treatment was used on some devices before the application of the carbon paste. Figure 5a shows the current density vs. voltage (J-V) characteristics in dark and under AM1.5 simulated solar spectrum at $1000 \mathrm{~W} / \mathrm{m}^{2}$ at $25 \pm 2{ }^{\circ} \mathrm{C} . \mathrm{Cs}_{2} \mathrm{PtI}_{6}$ show high open circuit voltage $\left(\mathrm{V}_{\mathrm{oc}}\right)$ $1.07 \mathrm{~V}$ and $1.2 \mathrm{~V}$ with and without EDA, and a short-circuit current density $\left(\mathrm{J}_{\mathrm{sc}}\right)$ of $\sim 20 \mathrm{~mA} / \mathrm{cm}^{2}$ corresponding to a maximum EQE of $65 \%$. These devices show low $\mathrm{V}_{\text {oc }}$ deficit which agrees well with low radiative recombination also determined by the high minority carrier diffusion length. With the use of EDA an improvement in FF is observed indicating passivation of grains and pinholes. A decrease in $\mathrm{V}_{\mathrm{oc}}$ of about $100 \mathrm{mV}$ is also observed with the use of EDA, which is within the standard deviation of the data. The EQE spectrum shows integrated current density (Int. $\mathrm{J}_{\mathrm{sc}}$ ) of $17.9 \mathrm{~mA} / \mathrm{cm}^{2}$ and $18.8 \mathrm{~mA} / \mathrm{cm}^{2}$ for devices with and without EDA. These integrated $\mathrm{J}_{\mathrm{sc}}$ values are smaller than $\mathrm{J}_{\mathrm{sc}}$ estimated by JV measurements indicating voltage dependent current collection due to photoconductivity of ETL. EQE curves show band edge at 840- $860 \mathrm{~nm}$ agreeing well with UVVis determined absorption edge and PL bandgap. The low FF for the devices can be attributed to the high series resistance estimated as $\sim 14 \mathrm{ohm} \mathrm{cm}^{2}$ for champion device and light-dark JV curve crossover in forward bias. Further reduction of pinhole to improve film quality and reduction in perovskite layer thickness should result in improvement of the fill-factor (FF). As shown in Figure 3, the EDA treatment slightly improved the carrier lifetime which can also contribute to the improvement in device FF due to improved carrier collection. It should be noted however, the 
difference in carrier lifetime may be due to sample-to-sample variation and other factors such as reduced parasitic resistance can also contribute to improved FF. Better quality and stable electron transport layer (wider bandgap than $\mathrm{CdS}$ ) may be needed to improve $\mathrm{J}_{\mathrm{sc}}$ by allowing transmission of more blue photons. The overall EQE improvement can also be expected by improvement of film quality in particular reduction of deep trap states, film thickness and interface recombination. Better quality electron and hole transport materials, reduction in perovskite thickness and improved film quality, can improve PCE further for $\mathrm{Cs}_{2} \mathrm{PtI}_{6}$ devices. Note that no hysteresis in forward and reverse scans was observed in these devices. Device performance data from 10 different devices of each type is shown in Figure 5c. The best device efficiencies for $\mathrm{Pb}$-free materials are reported for $\mathrm{CsGe}_{0.5} \mathrm{Sn}_{0.5} \mathrm{I}_{3}$ and (PEA,FA) $\mathrm{SnI}_{3}$ as close to $10 \%$, therefore, these Pt based materials clearly offer potentially stable and $\mathrm{Pb}$-free alternatives to existing (FA,MA,Cs) $\mathrm{Pb}(\mathrm{I}, \mathrm{Br})_{3}$ devices.

Halide perovskites are known for low formation and decomposition energies, therefore we tested the thermal stability of $\mathrm{Cs}_{2} \mathrm{PtI}_{6}$ phase prepared by solution process using differential scanning calorimetry. Figure 6a shows the DSC data collected on $\mathrm{Cs}_{2} \mathrm{PtI}_{6}$ pellets with decomposition between $525^{\circ} \mathrm{C}-575^{\circ} \mathrm{C}$, significantly higher than $130{ }^{\circ} \mathrm{C}$ for $\mathrm{MAPbI}_{3} \cdot{ }^{[36]} \mathrm{Cs}_{2} \mathrm{PtI}_{6}$ films were also exposed to AM1.5 $\mathrm{G}$ at $65^{\circ} \mathrm{C}$ for 1000 hours with $\mathrm{UV}$-Vis and XRD measurements to determine the bandgap and structure thereafter. Figures $6 \mathrm{~b}$ and $6 \mathrm{c}$ shows no change in the absorbance data or the $\mathrm{Cs}_{2} \mathrm{PtI}_{6}$ diffraction peaks. Devices tested under AM1.5 G at $65{ }^{\circ} \mathrm{C}$ for 500 hours shows a decrease in $V_{\text {oc }}$ and FF due to device shunting as shown in Figure 6d. The shunts are expected to develop due to pinholes in the $\mathrm{Cs}_{2} \mathrm{PtI}_{6}$ films and can be improved with film quality. These device improvements and detailed device stability analysis will be discussed elsewhere.

In summary, we have reproducibly created high quality thin-films of $\mathrm{Pb}$-free perovskite $\mathrm{Cs}_{2} \mathrm{PtI}_{6}$ via atmospheric solution process with experimentally determined bandgap of $\sim 1.4 \mathrm{eV}$. $\mathrm{Cs}_{2} \mathrm{PtI}_{6}$ crystallizes in a cubic crystal structure with the space group $F m \overline{3} m$, with a lattice parameter of about $8.3 \dot{A}$ with high $\{111\}$ peak intensities. SEM analysis shows well-formed micron-sized This article is protected by copyright. All rights reserved 
crystallites with improved film density with the use of ethylene diamine treatment. These atmospherically processed films contains low oxygen levels (mostly surface $\mathrm{CsO}_{\mathrm{x}}$ ) and $\mathrm{Cl}$ impurity from $\mathrm{PtI}_{4}$ precursors as determined by EDS, ToFSIMS and XPS. $\mathrm{Cs}_{2} \mathrm{PtI}_{6}$ shows enhanced stability and excellent optical absorption, hole mobility and minority carrier lifetimes. Generally, the Pb-free perovskites have substituted $\mathrm{Pb}^{2+}$ with homovalent $\mathrm{Sn}^{2+}$ in $\mathrm{AMX}_{3}$ structures, resulting in a stability issue due to conversion to $\mathrm{Sn}^{4+}$. The layered perovskite variant $\mathrm{A}_{2} \mathrm{BX}_{6}$ structures are an interesting alternative with improved stability due to the strong covalency of the $\left[\mathrm{BX}_{6}\right]^{2-}$ clusters. However, no $\mathrm{Pb}$-free perovskite material has yet shown a combination of high optical absorption and minority carrier diffusion lengths $>1 \mu \mathrm{m}$ like $\mathrm{MAPbI}_{3}$. For the first time we have demonstrated a $\mathrm{Pb}$-free halide perovskite material, $\mathrm{Cs}_{2} \mathrm{PtI}_{6}$, with high absorption coefficient compared to $\mathrm{MAPbI}_{3}$ and minority carrier lifetime $>2 \mu \mathrm{s}$. The high absorption coefficient in $\mathrm{Cs}_{2} \mathrm{PtI}_{6}$ results from the stronger $d-p$ transitions as compared to the $p-p$ transitions in $\mathrm{MAPbI}_{3}$. The combination of high absorption coefficient and high minority carrier diffusion lifetime in $\mathrm{Cs}_{2} \mathrm{PtI}_{6}$ suggests presence of directindirect transition behavior similar to $\mathrm{MAPbI}_{3}$, perhaps due to high $\mathrm{Z}$ of Pt. Superstrate $n-i-p$ devices with FTO/CdS/Cs ${ }_{2} \mathrm{PtI}_{6} /$ carbon/Cu have been reported for the first time, with maximum PCE of $13.88 \%$ and low $\mathrm{V}_{\mathrm{oc}}$ deficit. Further improvement in device efficiency is envisioned with the improvement of $\mathrm{Cs}_{2} \mathrm{PtI}_{6}$ film quality and better selection of ETL and HTL materials. It is noted that cost of Pt-based precursors is higher compared to Pb-based precursors, ${ }^{[42]}$ however, Pt offers a model system for $\mathrm{Pb}$-free perovskite materials and may offer a pathway to ultra-thin wide bandgap top cells for tandem solar cells. The key advantages of $\mathrm{Cs}_{2} \mathrm{PtI}_{6}$ over $\mathrm{MAPbI}_{3}$ include high stability, absorption coefficient, minority carrier lifetimes and tunable bandgap for applications beyond photovoltaics such as water splitting, photocatalytic $\mathrm{CO}_{2}$ reduction, and other optoelectronic devices.

\section{EXPERIMENTAL AND THEORY SECTION}


$\mathrm{Cs}_{2} \mathrm{PtI}_{6}$ films were fabricated through precursor-based solution processing (Figure 1) in atmospheric conditions. 0.25 - $0.4 \mathrm{M}$ solution of Cesium Iodide and Platinum (IV) Iodide (AlfaAesar CAS: 7790-46-7) solutes with a molar ratio of 1:1 was prepared in DMF and DMSO (SigmaAldrich CAS 68-12-2 and 67-68-5) and 50-50 volumetric mixtures thereof. The precursor solution was mixed at $80^{\circ} \mathrm{C}$ for 2.5 hours, drop casted and spread using a doctor blade technique onto preheated glass substrate at $70{ }^{\circ} \mathrm{C}$. The substrates were then annealed in a vacuum oven at -15 in $\mathrm{Hg}$ and $100{ }^{\circ} \mathrm{C}$ for one hour. An ethylene diamine (EDA) spray treatment was applied on some films followed by a $100^{\circ} \mathrm{C}$ anneal in vacuum for $30 \mathrm{~min}$. Film samples were stored in a nitrogen filled glovebox after annealing before further device processing. X-ray diffraction measurements were carried out on a Bruker diffractometer under ambient conditions using CuKaradiation. Vesta was used to create crystal structure and PDF-4 was used for X-ray diffraction data analysis and phase identification. Optical transmittance and reflectance measurements were performed using Shimadzu UV-2600 spectrophotometer followed by a Tauc analysis to determine optical bandgap of the thinfilm samples on glass. Devices with area of $0.25 \mathrm{~cm}^{2}$ were processed on $\mathrm{F}: \mathrm{SnO}_{2}$ (FTO) and chemical bath deposited (CBD) cadmium sulfide (CdS) followed by perovskite absorber deposition, annealing at $100{ }^{\circ} \mathrm{C}$ for one hour. Carbon paste ElectroDAG 440B from Acheson followed by annealing at $100^{\circ} \mathrm{C}$ for one hour. In some films ethylene diamine (EDA; 1, 2- Diaminoethane; Sigma Aldrich CAS Number 107-15-3) was sprayed and annealed before application of carbon paste. The front contact was formed by indium paste and the back contact was formed by $\mathrm{Cu}$ tape attached to the carbon paste. For CdS deposition, a mixture of $22 \mathrm{ml}$ of $0.015 \mathrm{M} \mathrm{CdSO}_{4}, 28 \mathrm{ml}$ of $\mathrm{NH}_{4} \mathrm{OH}$ in $150 \mathrm{ml}$ of deionized water was heated to a temperature of $65^{\circ} \mathrm{C}$, Tec10 glass was submerged for 1 minute and $22 \mathrm{ml}$ of $0.75 \mathrm{M}$ Thiourea was added and additionally stirred for 12 mins, with an expected CdS thickness of 80-100 nm. The sample was then dried with $\mathrm{N}_{2}$ flow and annealed in ambient on a hot plate at $120^{\circ} \mathrm{C}$ for 5 mins to get rid of residual $\mathrm{H}_{2} \mathrm{O}$. Current-voltage characteristics were measured using an ABET solar simulator calibrated to 1 sun and a Keithley 2400 sourcemeter with a $10 \mathrm{mV}$ step size. The external quantum efficiency (EQE) spectra were This article is protected by copyright. All rights reserved 
obtained using QE XL+ tool from PV Measurements Inc. consisting of a xenon lamp, a monochromator, a lock-in amplifier, and calibrated $\mathrm{Si}$ and $\mathrm{Ge}$ photodetectors. For quantum efficiency, the integrated quantum efficiency (IQE) or integrated $\mathrm{J}_{\mathrm{sc}}$ was solved via

$$
I Q E=\int_{\lambda_{\text {start }}}^{1200 \mathrm{~nm}} \frac{q \lambda}{h c}\left(\frac{Q E}{100}\right) E_{0, A M 1.5}(\lambda) d \lambda
$$

with $\mathrm{E}_{0}, \mathrm{AM} 1.5$ as the $\mathrm{AM} 1.5 \mathrm{G}$ spectral irradiance, $\mathrm{QE}$ as the quantum efficiency, and $\mathrm{q}$ as the elementary unit charge.

Raman spectra were measured using WiTec Laser Confocal/Raman Microscope with $532 \mathrm{~nm}$ laser. Lateral and depth distribution of the films were measured by TOF-SIMS profiling, and 3D imaging using an ION-TOF ToF-SIMS V instrument. Dual-beam depth profiling was completed with a $150 \times 150 \mu \mathrm{m}^{2}$ primary-beam area, and a $500 \times 500 \mu \mathrm{m}^{2}$ sputter-beam raster. A $30 \mathrm{keV} \mathrm{Bi}^{1+}$ beam was used as an analysis beam, which was scanned on the center of the sputtered crater. A 1 $\mathrm{keV} \mathrm{O}^{2+}$ beam or a $2 \mathrm{keV} \mathrm{Cs}^{+}$beam was used as a sputter beam with beam current of $255 \mathrm{nA}$ and $157 \mathrm{nA}$, respectively. Photoluminescence (PL) and time-resolved photoluminescence (TRPL) measurements were conducted at Molecular Foundry using a setup built around a Nikon Eclipse Ti$\mathrm{U}$ microscope with $0.3 \mathrm{NA}$ objective. For one photon excitation a $405 \mathrm{~nm}$ nanosecond pulsed laser system (Thorlabs NPL41B, 6ns pulse width, 1MHz repetition rate) has been used and PL was filtered with 540nm and 532nm long-pass filters.

Density Functional Theory (DFT) calculations were performed to clarify the electronic properties of $\mathrm{Cs}_{2} \mathrm{PtI}_{6}$ in comparison with $\mathrm{MAPbI}_{3}$. All calculations were performed using the GPAW code ${ }^{[43,44]}$ and the Atomic Simulation Environment (ASE). ${ }^{[17]}$ In order to obtain reliable results, we have calculated the electronic properties using the GLLB-SC functional ${ }^{[45]}$ with a density of $5 \mathrm{k}$-point $/ \AA$ and the spin-orbit coupling correction. This functional includes an estimation of the derivative discontinuity and has shown good accuracy with respect to more sophisticated methods and 
experimental values. ${ }^{[46-48]}$ Details about the methodology used to calculate the absorption spectrum can be found here. ${ }^{[49,50]}$

\section{KEYWORDS}

$\mathrm{Cs}_{2} \mathrm{PtI}_{6}$; halide perovskite solar cells; Air stable; Pb-free; stability.

\section{ACKNOWLEDGMENT}

Dr. Jim Sites at Colorado State University in Fort Collins, CO for providing FTO substrates with chemical bath deposited CdS. IEC acknowledge support from the Department of Energy Conversion and Storage, Technical University of Denmark, through the Special Competence Initiative “Autonomous Materials Discovery (AiMade)".

\section{REFERENCES}

1. "Best Research-Cell Efficiency Chart," [Online]. Available: https://www.nrel.gov/pv/cellefficiency.html.

2. M. A. Green, E. D. Dunlop, D. H. Levi, J. Hohl-Ebinger, M. Yoshita, N. Kopidakis, A. W. Y. Ho-Bailie, Prog. In Photovolt., 2020, 28, 3. https://doi.org/10.1002/pip.3228.

3. A. Kojima, K. Teshima, Y. Shirai and T. Miyasaka J. Am. Chem. Soc., 2009, 131, 17, 6050. https://doi.org/10.1021/ja809598r.

4. W. S. Yang, B.-W. Park, E. H. Jung, N. J. Jeon, Y. C. Kim, D. U. Lee, S. S. Shin, J. Seo, E. K. Kim, J. H. Noh and S. I. Seok, Science, 2017, 356, 6345, 1376. DOI: 10.1126/science.aan2301.

5. W.-J. Yin, T. Shi and Y. Yan, Adv. Mater., 2014, 26, 4653. https://doi.org/10.1002/adma.201306281. 
6. W. S. Yang, J. H. Noh, N. J. Jeon, Y. C. Kim, S. Ryu, J. Seo and S. I. Seok, Science, 2015, 348, 6240, 1234. DOI: 10.1126/science.aaa9272.

7. Y. Rong, L. Liu, A. Mei, X. Li and H. Han, Adv. Energy Mat., 2015, 5, 1501066. https://doi.org/10.1002/aenm.201501066.

8. Y. Yang and J. You, Nature, 2017, 544, 155. doi:10.1038/544155a.

9. N. J. Jeon, H. Na, E. H. Jung, T.-Y. Yang, Y. G. Lee, G. Kim, H.-W. Shin, S. I. Seok, J. Lee and J. Seok, Nat. Energy, 2018, 3, 682. https://doi.org/10.1038/s41560-018-0200-6.

10. S. N. Habisreutinger, D. P. McMeekin, H. J. Snaith and R. J. Nicholas, APL Mater., 2016, 4, 091503. https://doi.org/10.1063/1.4961210.

11. M. Saliba, T. Matsui, J.-Y. Seo, K. Domanski, J.-P. Correa-Baena, M. K. Nazeeruddin, S. M. Zakeeruddin, W. Tress, A. Abate, A. Hagfeldt and M. Gratzel, Energy Environ. Sci., 2016, 9, 6, 1989. https://doi.org/10.1039/C5EE03874J.

12. E. Jokar, C.-H. Chien, C.-M. Tsai, A. Fathi and E. W.-G. Diau, Adv. Mater., 2019, 31, 1804835. https://doi.org/10.1002/adma.201804835.

13. C. H. Ng, K. Nishimura, N. Ito, K. Hamada, D. Hirotani, Z. Wang, F. Yang, S. Iikubo, Q. Shen, K. Yoshino, T. Minemoto, S. Hayase, Nano Energy, 2019, 58, 130. https://doi.org/10.1016/j.nanoen.2019.01.026.

14. M. Chen, M.-G. Ju, H. F. Garces, A. D. Carl, L. K. Ono, Z. Hawash, Y. Zhang, T. Shen, Y. Qi, R. L. Grimm, D. Pacifici, X. C. Zheng, Y. Zhou and N. P. Padutre, Nat. Comm., 2019, 10, 1, 16. https://doi.org/10.1038/s41467-018-07951-y.

15. T. Krishnamoorthy, H. Ding, C. Yan, W. L. Leong, T. Baikie, Z. Zhang, M. Sherburne, S. Li, M. Asta, N. Matthews and S. G. Mhaisalkar, J. Mat. Chem. A, 2015, 3, 23829. https://doi.org/10.1039/C5TA05741H.

16. J. J. Mortensen, L. B. Hansen and K. W. Jacobsen, Phys. Rev. B, 2005, 71, 035109. https://doi.org/10.1103/PhysRevB.71.035109. 
17. A. H. Larsen et al., J. Phys. Cond. Matrer, 2017, 29, 27, 273002. https://doi.org/10.1088/1361-648X/aa680e.

18. M. Kuisma, O. J., J. Enkovaara and T. T. Rantala, Phys. Rev. B, 2010, 82, 115106. DOI: 10.1103/PhysRevB.82.115106.

19. I. E. Castelli, T. Olsen, S. Datta, D. D. Landis, S. Dahl, K. S. Thygesen and K. W. Jacobsen, Energy Environ. Sci., 2012, 5, 2, 5814. DOI: 10.1039/C1EE02717D.

20. I. E. Castelli, J. M. Garcia-Lastra, F. Huser, K. S. Thygesen and K. W. Jacobsen, New J. Phys., 2013, 15, 105026. https://doi.org/10.1088/1367-2630/15/10/105026.

21. I. E. Castelli, J. M. Garcia-Lastra, K. S. Thygesen and K. W. Jacobsen, APL Mater., 2014, 2, 081514. https://doi.org/10.1063/1.4893495.

22. J. Yan, J. J. Mortensen, K. W. Jacobsen and K. S. Thygesen, Phys. Rev. B, 2011, 83, 24, 245122. https://doi.org/10.1103/PhysRevB.83.245122.

23. I. E. Catelli, K. S. Thygesen and K. W. Jacobsen, J. Mater. Chem. A, 2015, 3, 12343. https://doi.org/10.1039/C5TA01586C.

24. C. Ran, W. Gao, J. Li, X. Hou, M. G. Kanatzidis, Z. Wu, Joule, 2019, 3, 12, 3072. https://doi.org/10.1016/j.joule.2019.08.023.

25. A. Mishra, Z. Ahmad, F. Touati, R. A. Shakoor, M. K. Nazeeruddin, RSC Adv., 2019, 9, 11589. DOI: 10.1039/C9RA00200F.

26. M. Chen, M.-G. Ju, A. D. Carl, Y. Zong, R. L. Grimm, J. Gu, X. C. Zeng, Y. Zhou and N. P. Padutre, Joule, 2018, 2, 3, 558. https://doi.org/10.1016/j.joule.2018.01.009.

27. S. Weber, T. Rath, K. Fellner, R. Fischer, B. Kunert, T. Dimopoulos, A. Steinegger and G. Trimmel, ACS Appl. Energy Mater., 2019, 2, 539. https://doi.org/10.1021/acsaem.8b01572.

28. Y. Hu, T. Qiu, F. Bai, X. Miao and S. Zhang, J. Mater. Chem. A, 2017, 48, 5, 25258. https://doi.org/10.1039/C7TA08824H. 
29. F. Umar, J. Zhang, Z. Jin, I. Muhammad, X. Yang, H. Deng, K. Jahangeer, Q. Hu, H. Song and J. Tang, Adv. Optical Mater., $2019, \quad 7, \quad 1801368$. https://doi.org/10.1002/adom.201801368.

30. W. B. Dai, S. Xu, J. Zhou, J. Hu, K. Huang and M. Xu, Sol. Energy Mat. Sol. Cells, 2019, 192, 140. https://doi.org/10.1016/j.solmat.2018.12.031.

31. B.-W. Park, B. Philippe, X. Zhang, H. Rensmo, G. Boschloo and E. M. J. Johansson, Adv. Mater., 2015, 27, 43, 6806. https://doi.org/10.1002/adma.201501978.

32. A. Kulkarni, A. K. Jena, M. Ikegami and T. Miyasaka, Chem. Comm., 2019, 55, 28, 4031. https://doi.org/10.1039/C9CC00733D.

33. E. Greul, M. L. Petrus, A. Binek, P. Docampo and T. Bein, J. Mater. Chem. A, 2017, 5, 37, 19972. https://doi.org/10.1039/C7TA06816F.

34. K. Ahmad, S. N. Ansari, K. Natarajan, S. M. Mobin, ChemElectroChem, 2019, 6, 4, 1192. https://doi.org/10.1002/celc.201801322.

35. C. Ran, W. Gao, J. Li, X. Hou, M. G. Kanatzidis, Z. Wu, Joule, 2019, 3, 12, 3072. https://doi.org/10.1016/j.joule.2019.08.023.

36. A. Mishra, Z. Ahmad, F. Touati, R. A. Shakoor, M. K. Nazeeruddin, RSC Adv., 2019, 9, 11589. DOI: $10.1039 / C 9 R A 00200 F$.

37. Y. Cai, W. Xie, H. Ding, Y. Chen, K. Thirumal, L. H. Wong, N. Mathews, S. G. Mhaisalkar, M. Sherburne and M. Asta, Chem. Mater., 2017, 29, 7740. https://doi.org/10.1021/acs.chemmater.7b02013.

38. K. Nakada, Y. Matsumoto, Y. Shimoi, K. Yamada and Y. Furukawa, Molecules, 2019, 24, 626. doi: 10.3390/molecules24030626.

39. F. Guoa, Z. Lu, D. Mohanty, T. Wang, I. B. Bhat, S. Zhang, S. Shi, M. A. Washington, G.C. Wang and T.-M. Lu, Mater. Res. Lett., 2017, 5, 8, 540. DOI: 10.1080/21663831.2017.1346525. 
40. A. Kaltzoglou, M. Antoniadou, A. G. Kontos, C. C. Stoumpos, D. Perganti, E. Siranidi, V. Raptis, K. Trohidou, V. Psycharis, M. G. Kanatzidis and P. Falaras, J. Phys. Chem. C, 2016, 120, 11777. https://doi.org/10.1021/acs.jpcc.6b02175.

41. D. M. Calistru, L. Mihut, S. Lefrant and I. Baltog, J. Appl. Phys., 1997, 82, 11, 5391. https://doi.org/10.1063/1.366307.

42. (a) $\mathrm{PbI}_{2}$ cost $\sim \$ 3 /$ gm (Sigma Aldrich CAS number: 10101-63-0 ). Accessed Dec 20, 2019. https://www.sigmaaldrich.com/catalog/product/aldrich/203602?lang=en\&region=US.

PtI $_{2}$ cost \$128/gm (Sigma Aldrich CAS number: 7790-39-8). Accessed Dec 20, 2019. https://www.sigmaaldrich.com/catalog/product/aldrich/206059?lang=en\&region=US.

PtI $_{4}$ cost \$110/gm (Alfa Aesar CAS number: 7790-46-7). Accessed Dec 20, 2019. https://www.alfa.com/en/catalog/040401/.

43. J. J. Mortensen, L. B. Hansen and K. W. Jacobsen, Phys. Rev. B, 2005, 71, 035109. https://doi.org/10.1103/PhysRevB.71.035109.

44. J. E. A. Enkovaara, J. Phys. Cond. Matter, 2010, 22, 25, 253202. https://doi.org/10.1088/0953-8984/22/25/253202.

45. M. Kuisma, O. J., J. Enkovaara and T. T. Rantala, Phys. Rev. B, 2010, 82, 115106. DOI: 10.1103/PhysRevB.82.115106.

46. I. E. Castelli, T. Olsen, S. Datta, D. D. Landis, S. Dahl, K. S. Thygesen and K. W. Jacobsen, Energy Environ. Sci., 2012, 5, 2, 5814. DOI: 10.1039/C1EE02717D.

47. I. E. Castelli, J. M. Garcia-Lastra, F. Huser, K. S. Thygesen and K. W. Jacobsen, New J. Phys., 2013, 15, 105026. https://doi.org/10.1088/1367-2630/15/10/105026.

48. I. E. Castelli, J. M. Garcia-Lastra, K. S. Thygesen and K. W. Jacobsen, APL Mater., 2014, 2, 081514. https://doi.org/10.1063/1.4893495.

49. J. Yan, J. J. Mortensen, K. W. Jacobsen and K. S. Thygesen, Phys. Rev. B, 2011, 83, 24, 245122. https://doi.org/10.1103/PhysRevB.83.245122. 
50. I. E. Catelli, K. S. Thygesen and K. W. Jacobsen, J. Mater. Chem. A, 2015, 3, 12343. https://doi.org/10.1039/C5TA01586C.

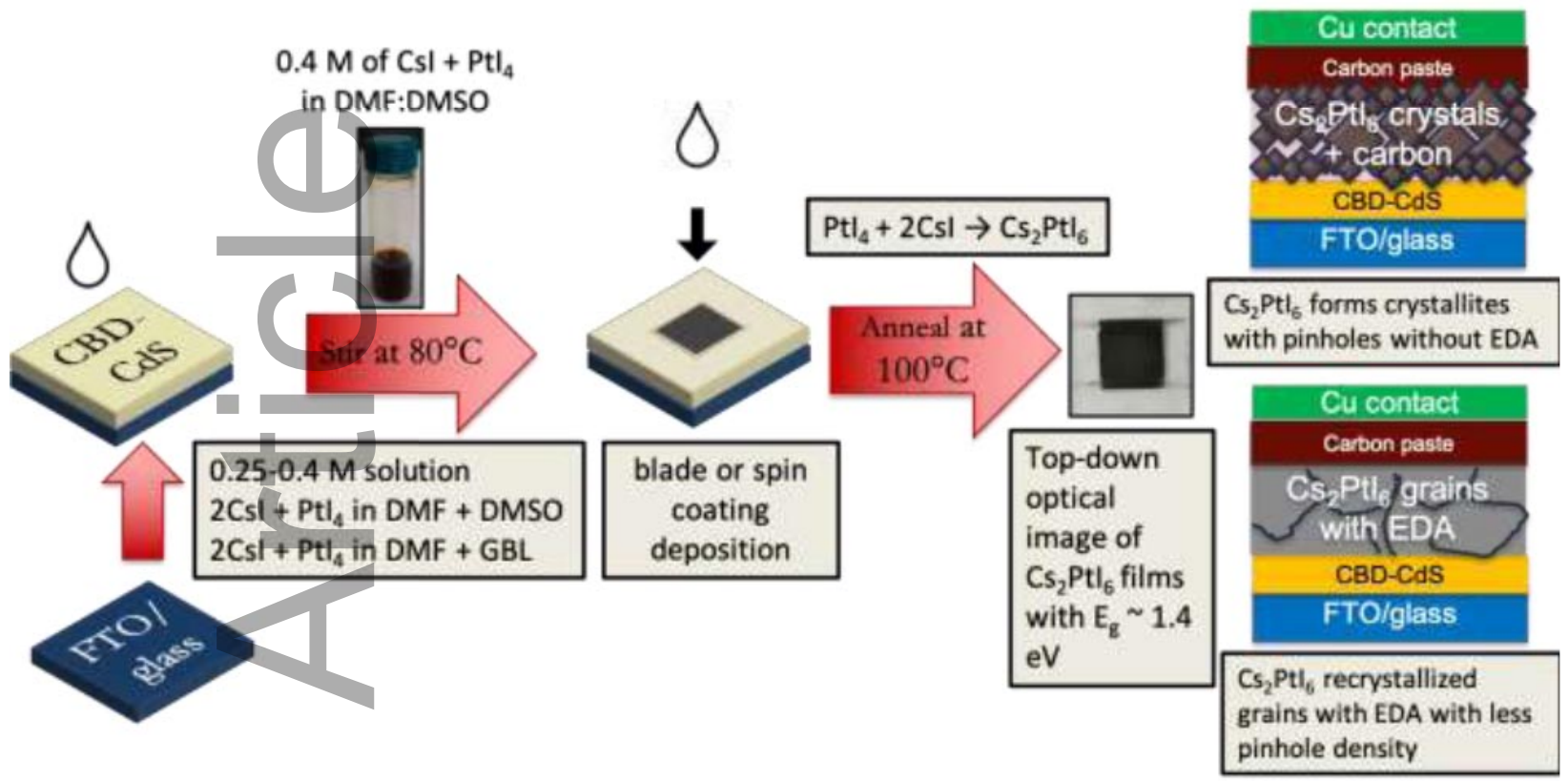

Figure 1. Schematic of atmospheric solution processing of $\mathrm{Cs}_{2} \mathrm{PtI}_{6}\left(\mathrm{E}_{\mathrm{g}} \sim 1.4 \mathrm{eV}\right)$ from precursors based on CsI and $\mathrm{PtI}_{4}$ prepared in solvent mixtures of DMF:DMSO by doctor blade or spin coating process. The use of ethylene diamine (EDA) treatment results in recrystallization of $\mathrm{Cs}_{2} \mathrm{PtI}_{6}$ resulting in formation of polycrystalline films with lesser density of pinholes.

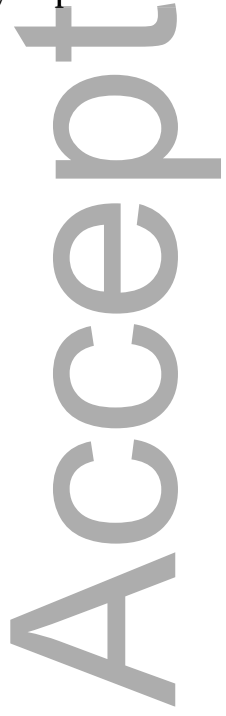

This article is protected by copyright. All rights reserved 

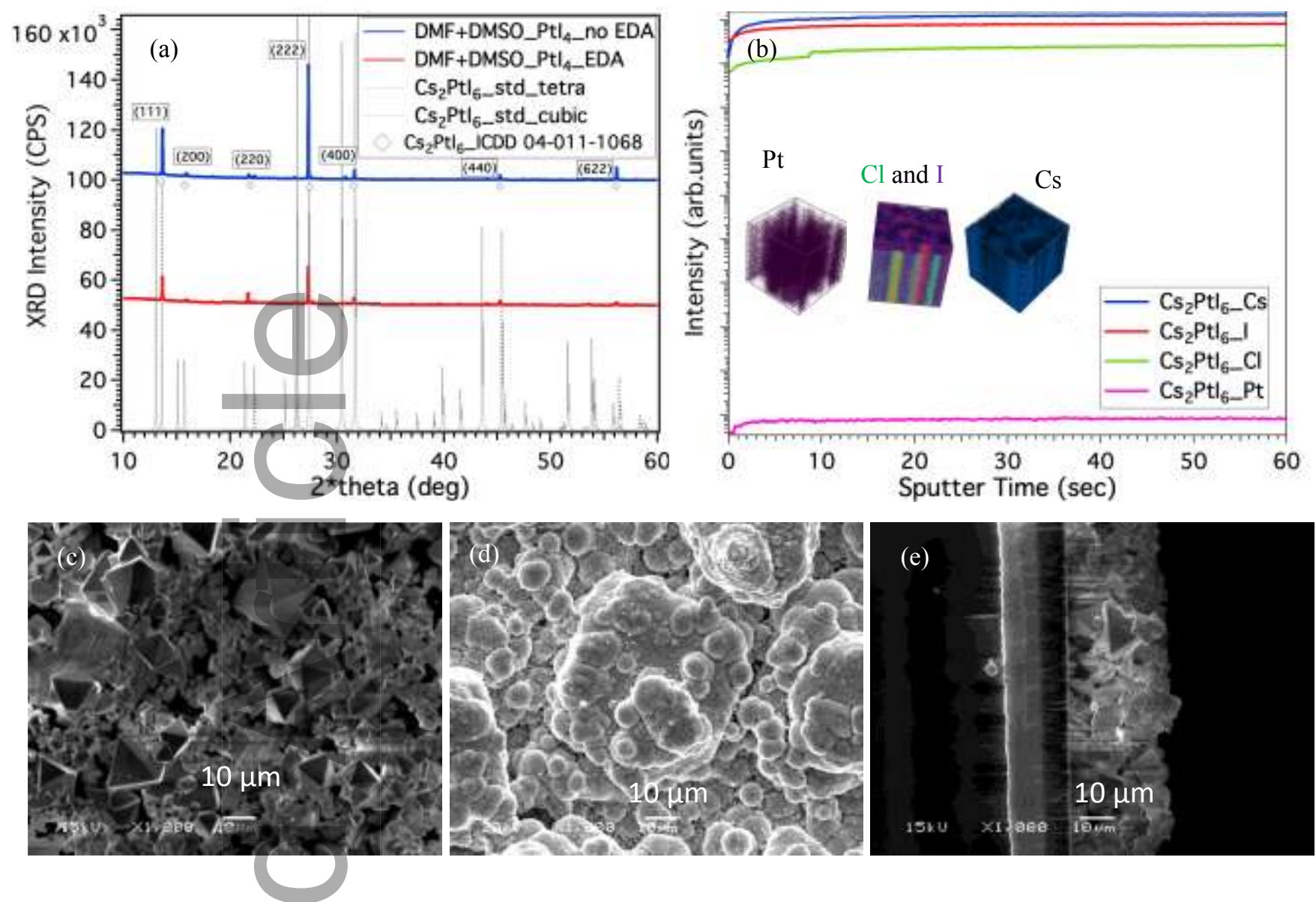

Figure 2. a) X-ray diffraction data for $\mathrm{Cs}_{2} \mathrm{PtI}_{6}$ films on glass with y-axis as XRD intensity in CPS or counts per second. The intensity has been offset on $\mathrm{Y}$-axis to about to clearly represent the data. b) Depth dependent ToF-SIMS concentration profiles and insets of 3-d renderings for $\mathrm{Cl}$, I, Pt and $\mathrm{Cs}$ for thin-films prepared using $\mathrm{PtI}_{4}$ based precursors in solvent mixture DMF:DMSO. Data presented as intensity of the elements on y-axis and sputter time through film thickness on x-axis. c-e) Top-down and cross-sectional SEM images for thin-films prepared with $\mathrm{PtI}_{4}$ based precursors in solvent mixtures of DMF:DMSO identified as $\mathrm{Cs}_{2} \mathrm{PtI}_{6}$, image (d) is after EDA treatment. Average film thickness of 10-15 $\mu \mathrm{m}$ has been obtained by doctor-blade process.

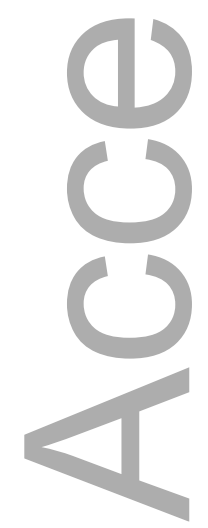

This article is protected by copyright. All rights reserved 

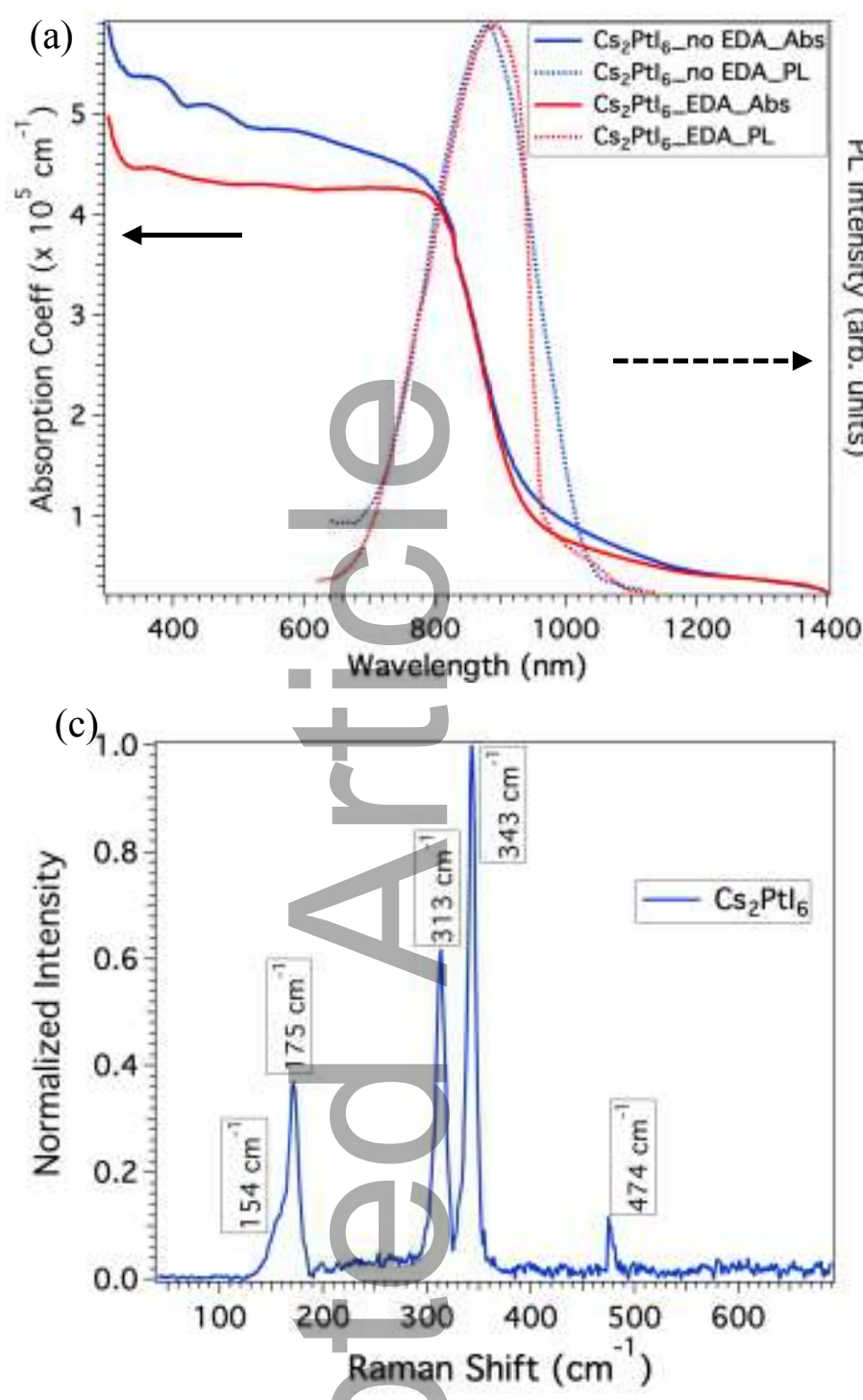

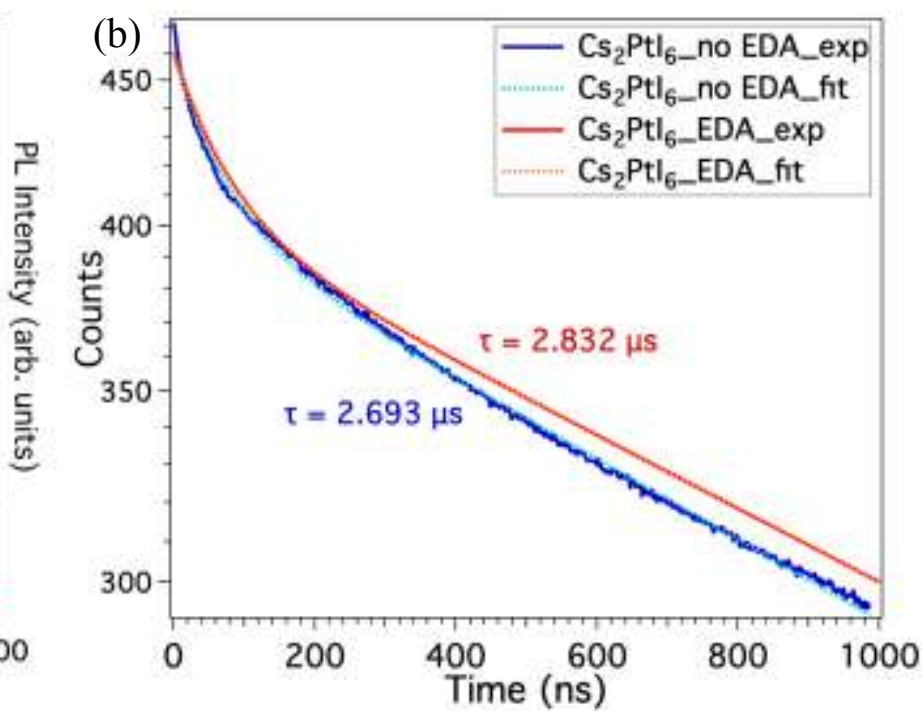

Figure 3. (a) UV-Vis absorption coefficient and PL emission spectra, (b) TRPL decay curves to determine minority carrier lifetime and (c) Raman spectra for $\mathrm{Cs}_{2} \mathrm{PtI}_{6}$ perovskite thin-films deposited on glass. 

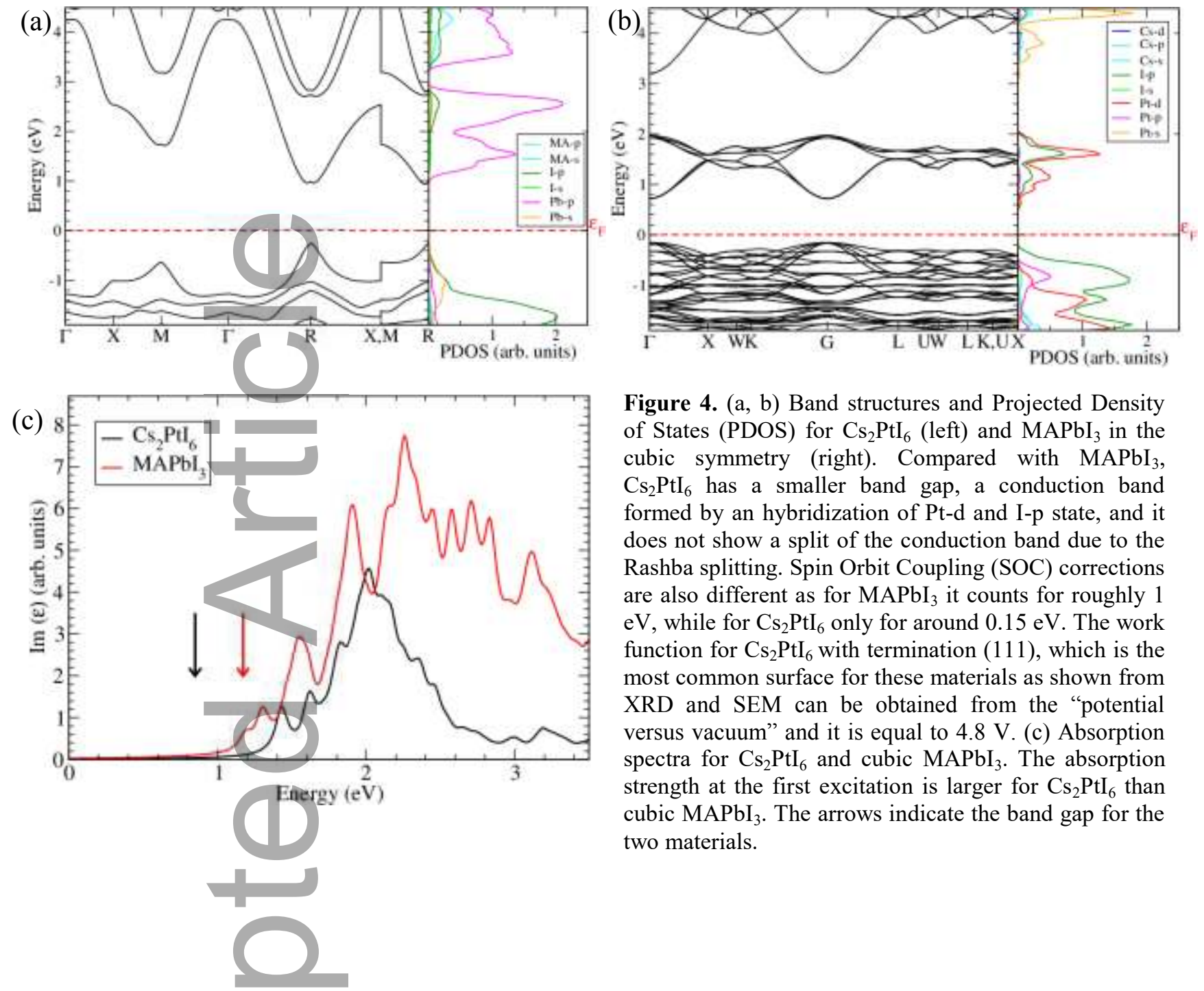

Figure 4. $(\mathrm{a}, \mathrm{b})$ Band structures and Projected Density of States (PDOS) for $\mathrm{Cs}_{2} \mathrm{PtI}_{6}$ (left) and $\mathrm{MAPbI}_{3}$ in the cubic symmetry (right). Compared with $\mathrm{MAPbI}_{3}$, $\mathrm{Cs}_{2} \mathrm{PtI}_{6}$ has a smaller band gap, a conduction band formed by an hybridization of Pt-d and I-p state, and it does not show a split of the conduction band due to the Rashba splitting. Spin Orbit Coupling (SOC) corrections are also different as for $\mathrm{MAPbI}_{3}$ it counts for roughly 1 $\mathrm{eV}$, while for $\mathrm{Cs}_{2} \mathrm{PtI}_{6}$ only for around $0.15 \mathrm{eV}$. The work function for $\mathrm{Cs}_{2} \mathrm{PtI}_{6}$ with termination (111), which is the most common surface for these materials as shown from XRD and SEM can be obtained from the "potential versus vacuum" and it is equal to $4.8 \mathrm{~V}$. (c) Absorption spectra for $\mathrm{Cs}_{2} \mathrm{PtI}_{6}$ and cubic $\mathrm{MAPbI}_{3}$. The absorption strength at the first excitation is larger for $\mathrm{Cs}_{2} \mathrm{PtI}_{6}$ than cubic $\mathrm{MAPbI}_{3}$. The arrows indicate the band gap for the two materials. 
(a)
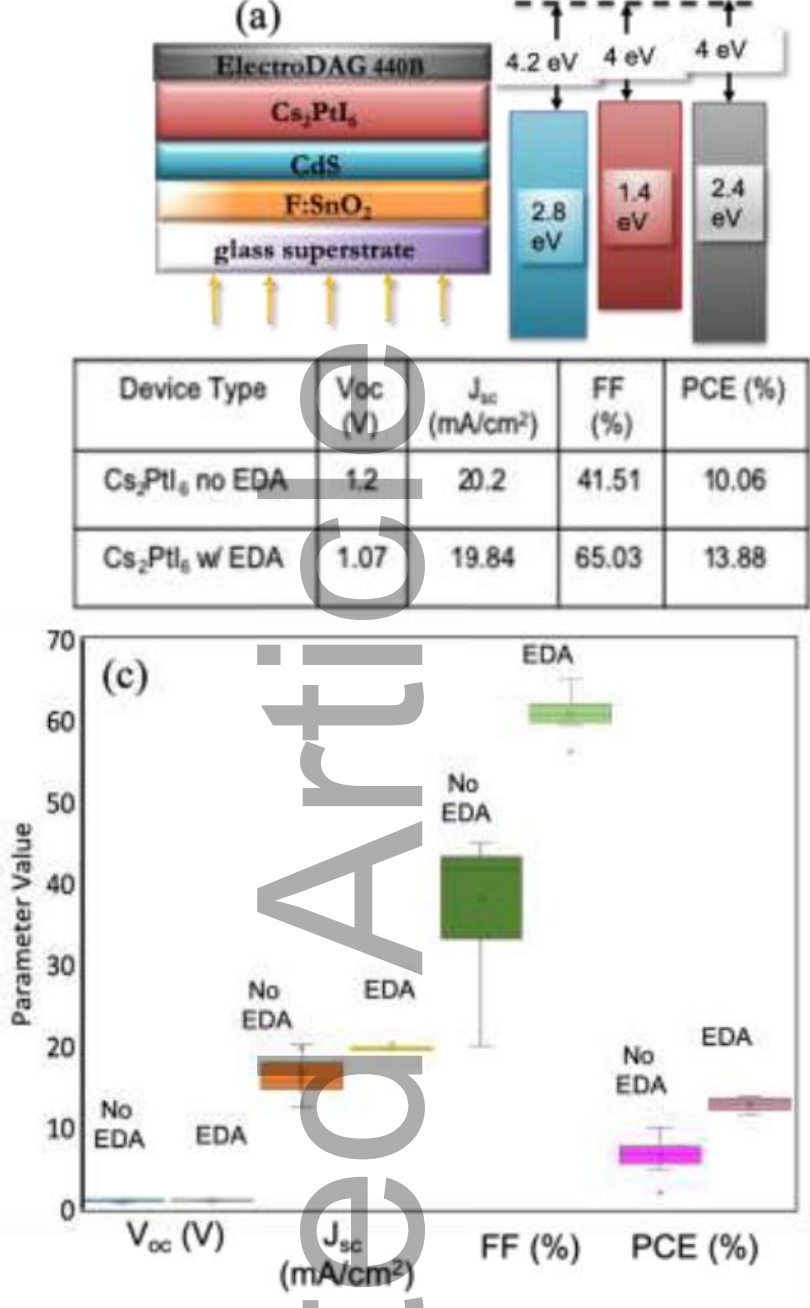
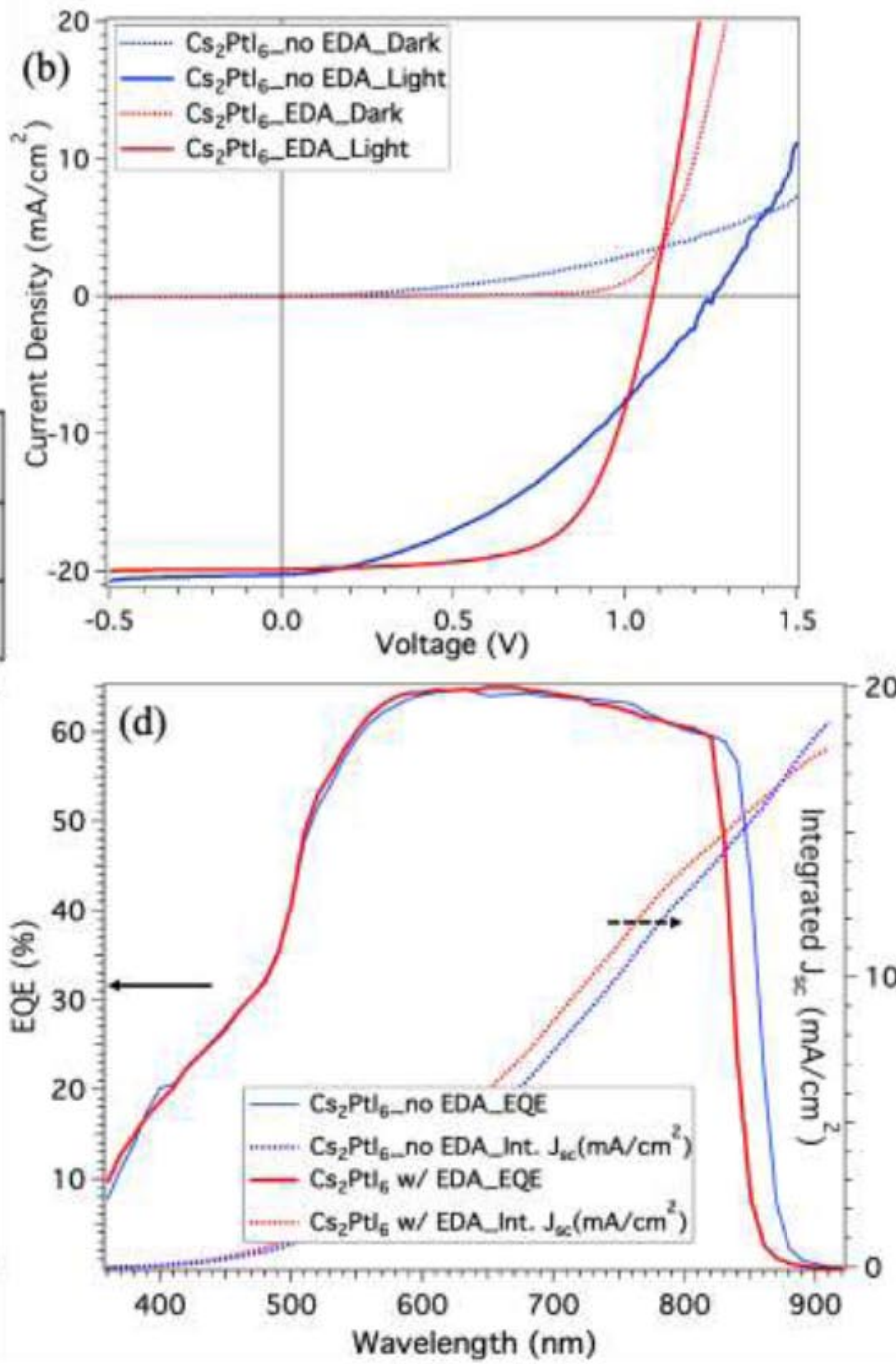

Figure 5. (a) Device stack for thin-film superstrate $n-i-p$ devices fabricated in this study $\mathrm{F}: \mathrm{SnO}_{2}$ (FTO) $/ \mathrm{CdS} / \mathrm{Cs}_{2} \mathrm{PtI}_{6} / \mathrm{Carbon} / \mathrm{Cu}$ and estimated band alignments (b) Dark and light current density - voltage (JV) curves with table showing device power conversion efficiency (PCE), open circuit voltage $\left(\mathrm{V}_{\mathrm{oc}}\right)$, short-circuit current density $\left(\mathrm{J}_{\mathrm{sc}}\right)$, fill-factor $(\mathrm{FF})$ for best $\mathrm{Cs}_{2} \mathrm{PtI}_{6}$ devices prepared with and without $\mathrm{EDA}$ treatment. (c) PCE, $\mathrm{V}_{\mathrm{oc}}, \mathrm{J}_{\mathrm{sc}}$, $\mathrm{FF}$ distribution for 10 best devices of each type fabricated (c) External quantum efficiency (EQE) and Integrated $J_{\mathrm{sc}}\left(\mathrm{mA} / \mathrm{cm}^{2}\right)$ for $\mathrm{Cs}_{2} \mathrm{PtI}_{6}$ devices prepared with and without EDA treatment.

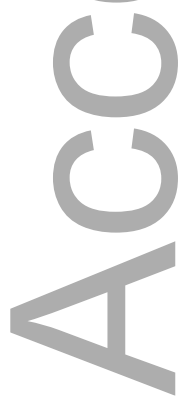


(a)
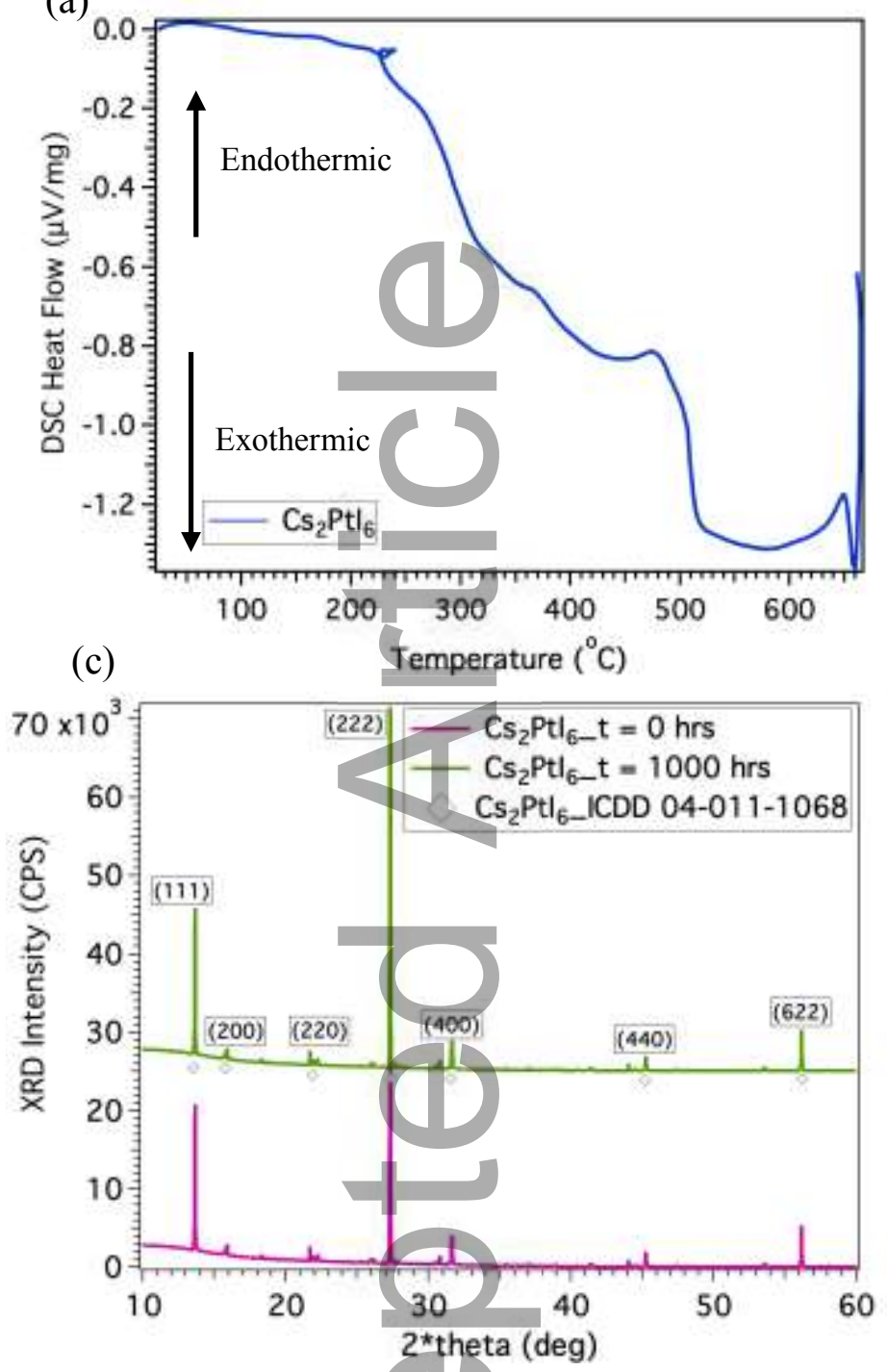

(b)

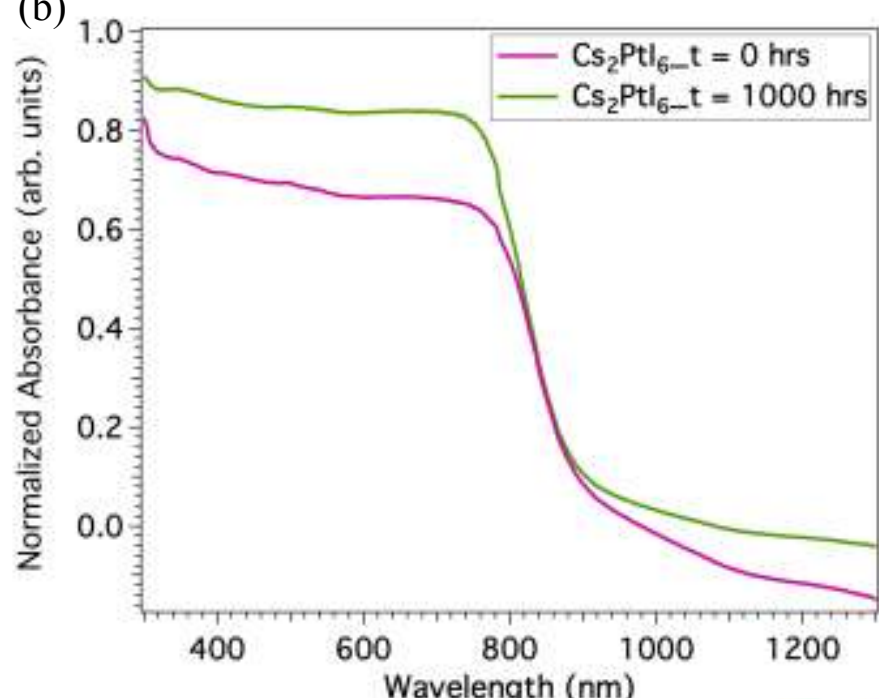

(d)

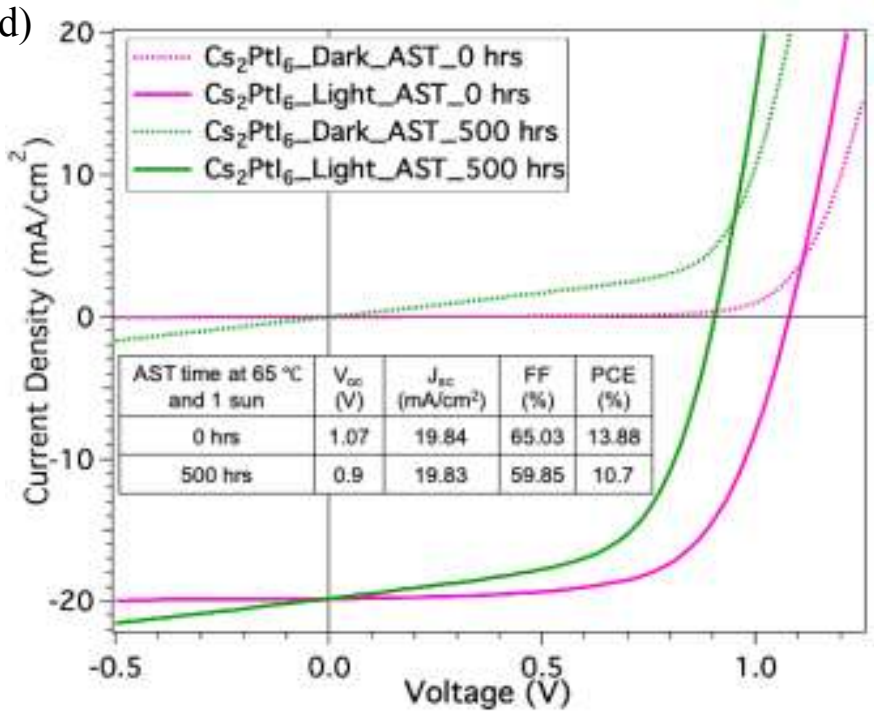

Figure 6. (a) Differential scanning calorimetry thermal profiles for $\mathrm{Cs}_{2} \mathrm{PtI}_{6}$ pellets prepared from the powder using the thin-film process described experimentation section (b) UV-Vis absorbance vs. photon wavelength and (c) XRD diffraction pattern for $\mathrm{Cs}_{2} \mathrm{PtI}_{6}$ thin-films on glass before and after accelerated stress test (AST) at $65{ }^{\circ} \mathrm{C}$ and $\mathrm{AM} 1.5 \mathrm{G}$ solar spectrum in air for 1000 hours. The intensity of $1000 \mathrm{hrs}$ data has been offset to clearly represent the data. (d) Dark and light current density - voltage (JV) curves with table showing device power conversion efficiency (PCE), open circuit voltage $\left(\mathrm{V}_{\mathrm{oc}}\right)$, short-circuit current density $\left(\mathrm{J}_{\mathrm{sc}}\right)$, fill-factor $(\mathrm{FF})$ for a representative $\mathrm{Cs}_{2} \mathrm{PtI}_{6}$ device before and after 500 hours of AST at $65^{\circ} \mathrm{C}$ and AM1.5G solar spectrum in air.

Air Stable, High Efficiency, Pt-Based Halide Perovskite Solar Cells with Long Carrier Lifetimes 
Cs2PtI6 with bandgap of $1.4 \mathrm{eV}$ is shown to be promising $\mathrm{Pb}$-free material for perovskite solar cells. These thin-films show a carrier lifetime of $>2 \square \mathrm{s}$, absorption coefficient of $4 \mathrm{x} \llbracket 10 \rrbracket^{\wedge} 5$ $\llbracket \mathrm{cm} \rrbracket^{\wedge}(-1)$, and superior thermal and atmospheric stability. A superstrate planar n-i-p device with an efficiency of $13.88 \%$ and low Voc deficit is demonstrated by solution processing.

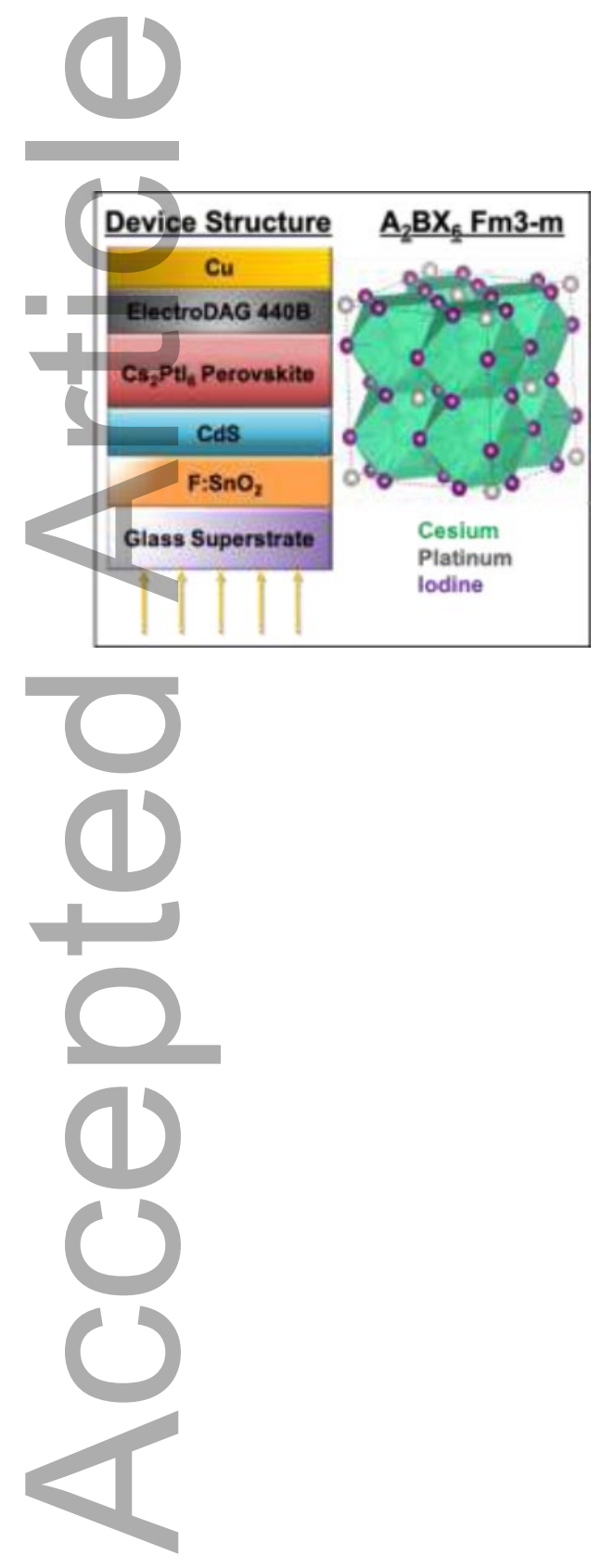

This article is protected by copyright. All rights reserved 